\title{
Measuring value in health care: What price are surgeons going to pay?
}

\author{
Francisco Igor Macedo, $\mathrm{MD},{ }^{\mathrm{a}}$ and Tomas A. Salerno, $\mathrm{MD}^{\mathrm{b}}$
}

\footnotetext{
From the ${ }^{\mathrm{a} D e w i t t-D a u g h t r y ~ D e p a r t m e n t ~ o f ~ S u r g e r y, ~ a n d ~}{ }^{\mathrm{b}}$ Division of Cardiothoracic Surgery and Jackson Memorial Hospital and the University of Miami Miller School of Medicine, Miami, Fla. Disclosures: Authors have nothing to disclose with regard to commercial support.

Received for publication April 9, 2018; accepted for publication April 10, 2018; available ahead of print May 8, 2018.

Address for reprints: Tomas A. Salerno, MD, Jackson Memorial Hospital and the University of Miami Miller School of Medicine, 1611 NW 12th Ave, Miami, FL 33136 (E-mail: tsalerno@med.miami.edu).

J Thorac Cardiovasc Surg 2018;156:1449-50

$0022-5223 / \$ 36.00$

Copyright (C) 2018 by The American Association for Thoracic Surgery

https://doi.org/10.1016/j.jtcvs.2018.04.048
}

Value of care is an evolving concept in which medical reimbursements will be based on outcomes divided by the cost of care delivered. "Perfect care" can be defined as an expedited and sustainable patient recovery with no impairment of health status after minimal health care cost spent. ${ }^{1}$ In other words, value means efficiency. Value-based health care has been advocated as a superior framework for performance improvement in health care.

In this issue of the Journal, Glotzbach and colleagues ${ }^{2}$ demonstrate the impact of value-driven care delivered to patients undergoing coronary artery bypass grafting. The compliance with 10 standard quality metrics used by the Society of Thoracic Surgeons was associated with decreased costs while maintaining optimal outcomes, thereby increasing the value of care delivered. The topic is very timely, because in 2017, the US Centers for Medicare and Medicaid Services merged its previous physician quality programs into the Merit-based Incentive Payment System. This is a paradigm shift in medical reimbursement from quantity-based fee-for-service payment models to qualitybased bundled-payment models.

Value-based reimbursement provides either bonus payments, penalties, or no bonus or penalties (neutral adjustment) to physicians' payments according to the quality and cost of the care that they provide. Despite its theoretic superiority, value-based care poses several major issues. There is increased concern that it will soon move toward a penalty-only phase, penalizing medical providers who are unable to meet certain outcomes thresholds. As a consequence, some surgeons may elect to deny care to certain high-risk patients, leading to changes in referral patterns. Fearing postoperative complications in high-risk patients, surgeons may decide to refer them to tertiary academic centers. This in turn, may potentially impose financial deficits on such institutions.

There is little doubt that health care in the United States needs to be more efficient to decrease its costs. Measuring value has become a national priority and a central driving

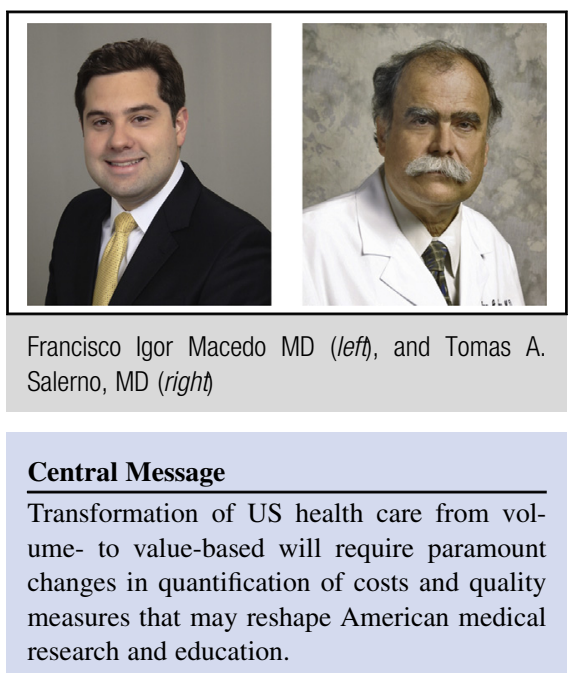

See Article page 1436.

force for health care. Although the concept of value may intuitively be easily understood, it has proved difficult to measure. Some of the costs associated with heart surgery, for example, are not qualitatively accounted for, such as medications, disposable instruments, or surgical devices. Companies' profits have remained large, while surgeons' reimbursements have continued to decline through the years. Physician noncompliance with certain qualityrelated metrics, such as the Society of Thoracic Surgeons quality metrics or the Merit-based Incentive Payment System, cannot be the only variable to be taken into account. Established organizations, such as the Society of Thoracic Surgeons and the American College of Surgeons, should seek solutions to improve quality of care while protecting their members. Surgeons remain under pressure to decrease costs, but they may not be capable of doing so, at least in an individualized way. Who should be penalized for increased costs (decreased value)? The surgeon, the pharmaceutical and supply companies, or the hospital? Are insurance companies retaining most of the profits while the hospitals are struggling to save costs? Although these questions remain unanswered, it is clear that much improvement needs to be undertaken to create accountability for sustainable and affordable health care.

Another important concern is that "optimization of costs" may disregard patient outcomes, leading to 
savings but limiting effective care. This may lead to standardization of care, which is not necessarily bad but definitely does limit innovation and medical research. There is a fine line of balance in this equation, and further discussion among medical providers, payers, and lawmakers should be undertaken before implementation. An open dialog among stakeholders involved in the care of patients should be encouraged as we head into uncharted territory.

\section{References}

1. Porter ME. What is value in health care? N Engl J Med. 2010;363:2477-81.

2. Glotzbach JP, Sharma V, Tonna JE, Pettit JC, McKellar SH, Eckhauser AW, et al. Value-driven cardiac surgery: achieving "perfect care" after coronary artery bypass grafting. J Thoracic Cardiovasc Surg. 2018;156:1436-48.e2. 